\title{
Enseñanza de la Anatomía. Uso de Medios en el Aula
}

\author{
Teaching of Anatomy. Use of Media in the Classroom
}

Julio L. Cárdenas Valenzuela ${ }^{1}$

\begin{abstract}
CÁRDENAS, V. J. L. Enseñanza de la anatomía. Uso de medios en el aula. Int. J. Morphol., 37(3):1123-1129, 2019.
RESUMEN: Poca información existe acerca de la evolución del uso de medios en la enseñanza de la anatomía moderna en sus primeros años. Esto se explica tal vez porque los académicos y estudiantes se preocuparon más del contenido que de los medios utilizados para la docencia morfológica obviamente. Su uso sin embargo es muy importante, pues modifica la forma de enseñar y de construir incluso los recintos donde se imparte la docencia, los que pasan de ser lugares con mucha iluminación natural de antaño, a ser recintos cerrados más bien obscuros y dotados de equipos con dispositivos proyectores de luz en la actualidad. El presente trabajo pretende por tanto dejar en la memoria de las nuevas generaciones los medios usados de antaño, el inicio de los medios audiovisuales en la década de los años 30 y el uso de TICs más recientemente y mostrar su evolución de la mano con los cambios tecnológicos en la enseñanza anatómica hasta nuestros días, no sólo a través de conocimientos generales al respecto, sino también a través de testimonios y documentos que los citan directamente en la docencia anatómica del país.
\end{abstract}

PALABRAS CLAVE: Enseñanza de la anatomía; Historia de la anatomía; Medios audiovisuales.

\section{INTRODUCCIÓN}

Siendo la anatomía, la histología, la embriología y la neuroanatomía ciencias que utilizan fundamentalmente las imágenes en su enseñanza, llama la atención la poca descripción que en la historia de estas ciencias existe con respecto al uso y evolución de los medios audiovisuales utilizados para su difusión en las aulas universitarias, especialmente si tomamos en consideración la importancia que ellas tienen en el desarrollo de la enseñanza (Adame Tomás, 2007).

En los inicios de la enseñanza formal de la medicina en Chile, con la enseñanza de la Prima de Medicina por la Real Universidad de San Felipe desde 1756, la anatomía no se enseñaba dentro del ámbito universitario, a pesar que dicha universidad existía desde 1738. El primer profesor de medicina sería Domingo Nevín, único condecorado como doctor en la Facultad de Medicina, y el primer alumno de medicina, fray Matías del Carmen Verdugo. En esos primeros momentos los registros señalan que se leían libros clásicos como Galeno e Hipócrates (Medina, 1928).

Luego, el padre Manuel Chaparro a fines del siglo XVIII recomendaría los de André Piquer, Lorenzo Heister (1683-1758) y la Anatomía Completa del hombre, del médico español Martín Martínez (1648-1734) no existiendo registro alguno del uso de un medio visual al respecto.
Esto cambiaría casi 100 años después en 1833, cuando surge la escuela de Medicina dependiente del Instituto Nacional, en que anatomía sí estaba considerada impartirla dentro de los estudios médicos formales. Lamentablemente, el Instituto Nacional duraría 1 año debido a la reconquista española. Luego de 10 años pasaría a depender de la naciente Universidad de Chile. La enseñanza de la anatomia se realizaba en esos años con alguna disertación luego de la disección, tal como lo hacía Augusto Orrego Luco a mediados del siglo XIX (Semir, 1860).

Cabe destacar que esta forma de enseñanza seguía los patrones inculcados por España y claramente se establecieron en otras universidades tanto del país como extranjeras con matices regionales. Así, libros franceses, algunos traducidos al español, libros españoles y otros ingleses traducidos fueron leídos por los profesores en la cátedra de anatomía (Cárdenas, 2017).

El uso de medios audiovisuales es posterior siguiendo una evolución que tiende a repetirse en todos los lugares donde se impartía la anatomía como se puede inferir del análisis fotográfico extranjero, cambios muchas veces resistidos en sus inicios, aceptados con el tiempo, dependiendo a veces del desarrollo local del país (Fig. 1).

\footnotetext{
${ }^{1}$ Departamento de Anatomia y Medicina Legal, Facultad de Medicina Universidad de Chile, Santiago, Chile.
} 


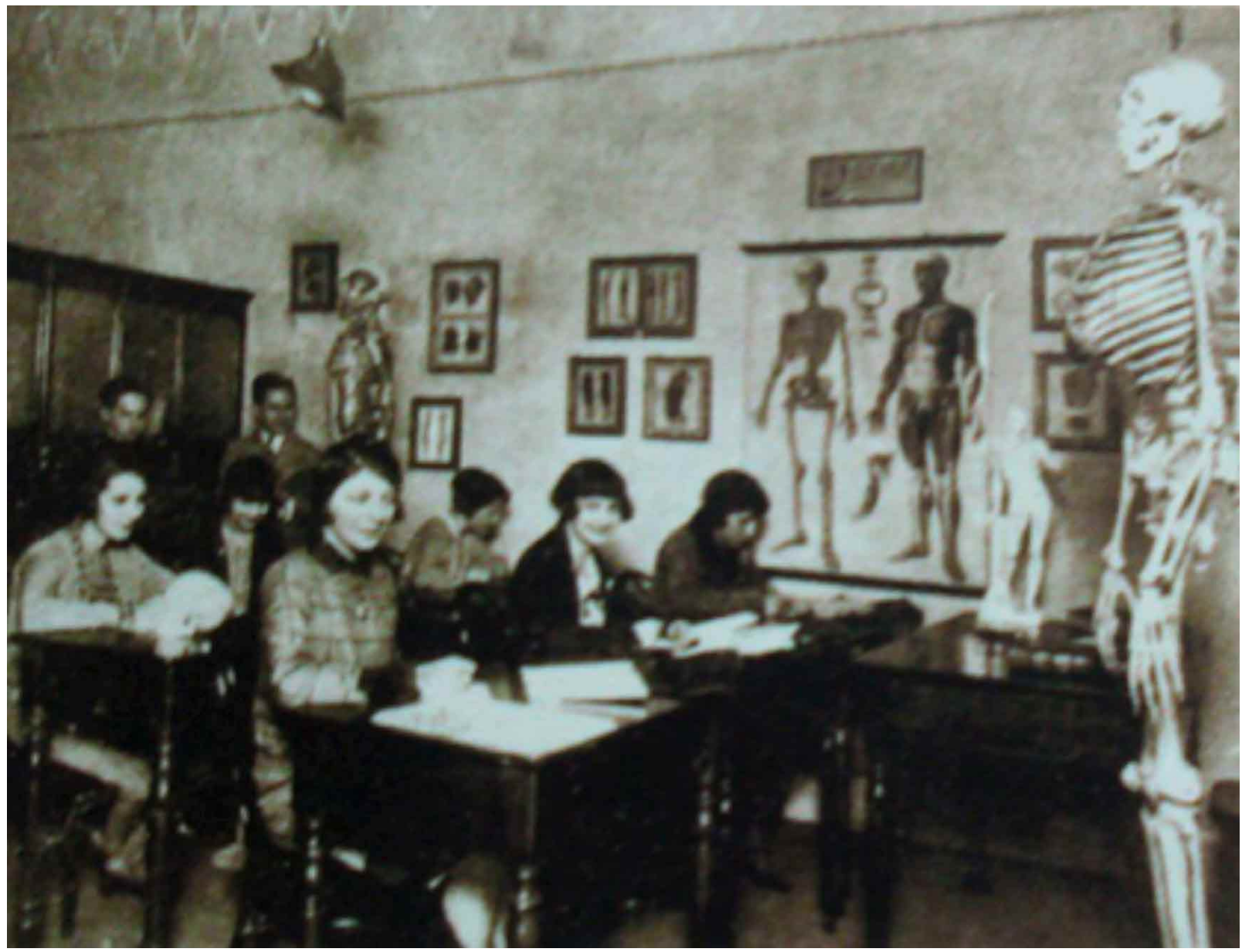

Fig. 1. Aula de anatomía en el Instituto de Artes de la UFRGS, 1928, Autor desconocido - escaneado por AVANCINI \& BULHÕES. Artistas Professores da UFRGS: Obras do Acervo da Pinacoteca Barão de Santo Ângelo do IA. Porto Alegre, Brasil.

\section{MATERIAL Y MÉTODO}

Se recopila información de documentos, archivos, publicaciones científicas, diarios, revistas, novelas autobiográficas, fotografías, relatos y entrevistas escritas y digitales que hacen alusión al estudio anatómico en Chile reuniendo los antecedentes relacionados con la metodología usada en la enseñanza de la anatomía, infiriendo en algunos casos el uso de los medios audiovisuales empleados.

\section{RESULTADOS}

De lo anterior, se muestra un compilado de los medios audiovisuales empleados en Chile para la docencia anatómica especialmente teórica, ordenados cronológicamente según aparición en su uso como son:

\section{A) Medios visuales primarios}

Son los primeros medios utilizados para la creación de imágenes y probablemente comenzron con la realización de dibujos sobre papel u otro medio de sostén para grupos de alumnos. No requieren uso de energía alguna y no proyectan imágenes a distancia. Dependen de la habilidad del realizador en forma directa.

Tiza y Pizarrón: A pesar de conocerse desde la época de los egipcios, la tiza, conocida también como gis ó yeso, sulfato de calcio hemidrato, deriva su nombre de la palabra nahualt "tizatl". Los primeros relatos al respecto sobre el uso de la tiza para la creación de dibujos en anatomía en Chile ubican al profesor David Benavente a fines de la segunda mitad del siglo XIX como un eximio dibujante habi- 
tual en dictar sus clases con dibujos realizados sobre los 2 juegos de pizarras de deslizamiento vertical que existían en el auditorio de anatomía de la escuela de Medicina de la Cañadilla. A pesar de ello, podriamos suponer que su uso es anterior a este relato.

La técnica consitía en realizar sus dibujos y una vez terminados éstos, alejarse para luego volver bruscamente a corregirlos y a colorearlos: "El caballero que trabaja aquí, llena estas pizarras de dibujos todo el tiempo. Y por Dios que dibuja bien. Mi compañero anda siempre buscando tiza todo el tiempo, porque el Dr. Benavente gasta muchísima." Elías, mozo de anatomía de la época (Guzmán Cortés, 1964). Las clases se realizaban hasta cerca de las 19 hrs. pues luego por ausencia de luz artificial, se hacía imposible seguir con las actividades. Luego de la clase, los alumnos iban con sus ayudantes Charlin y Basilio Muñoz Pal a ver los cadáveres. Estas pizarras de grafíto comenzarían a ser reemplazadas en la exposición de imágenes por retroproyectoras, diapocassetes en la década de los años 50 . Finalmente, las pizarras serían reeplazadas definitivamente por pizarras de acrílico con uso de marcadores de tinta delebles luego de 40 años, recién en la década de los 80 , en el desarrollo de esquemas o tablas durante clases (Fig. 2).

Láminas anatómicas: Teniendo este tipo de comunicación didáctica su apogeo en Europa entre los años 1870 y 1920, en Chile es el año de 1903 el que queda registrado como el año en el que se realizaría el cuadro anatómico más antiguo en la Universidad de Chile usado para la docencia; pertenece a Luis Vargas Salcedo, alumno en esa época que llegaría a estar a cargo de la cátedra de anatomía posteriormente (Fig. 3).

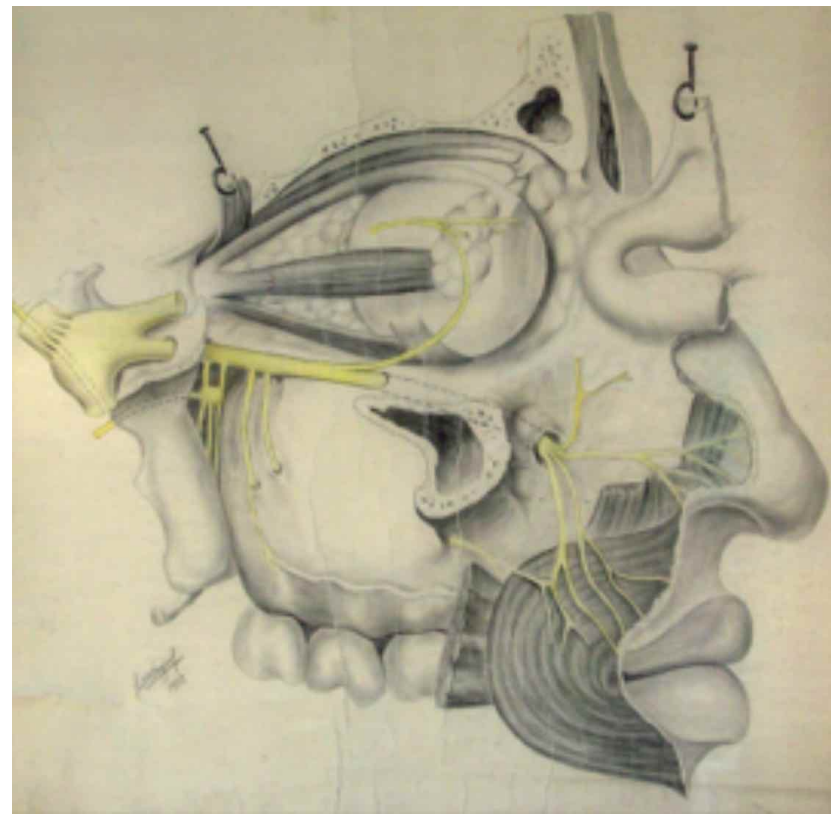

Fig. 3. Dibujo en lápiz grafito, distribución nervio maxilar. Instituto de Anatomía Universidad de Chile. Autor: Luis Vargas Salcedo, año 1903.

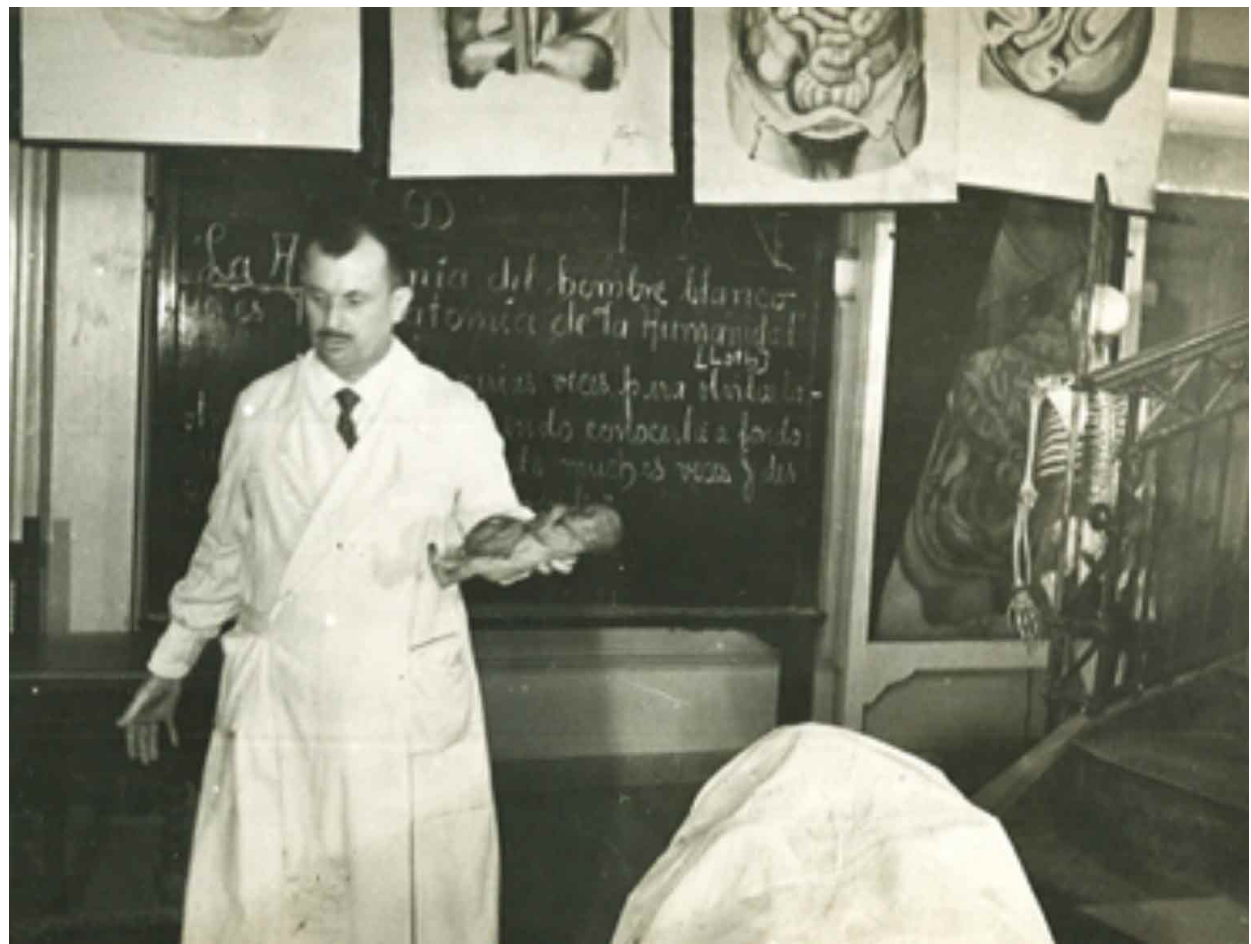

Fig. 2. Coexistencia de uso de pizarra y láminas anatómicas. Sala Virgilio Gómez, Universidad de Concepción. Autor desconocido, biblioteca central Facultad de Medicina Universidad de Chile 
Un impulso en el desarrollo de este medio sucedería en el año de 1913 cuando el profesor Basilio Muñoz Pal con ocasión de viajar a Berlín, y asistiendo a las clases de anatomía descriptiva de Waldayer, Tauber y Kopasch (Laval, 1964) trae los lienzos para realizar en forma programada ahora, la elaboración de estas láminas. Dispuestas en 13 áreas temáticas son más de 475 láminas que en la actualidad se conservan bajo el anfiteatro anatómico.

Sobre los autores de las láminas podemos señalar que participaron alumnos y profesores, futuros docentes como Enrique Solervicens y Luis Vargas Salcedo. Prueba de la calidad artística de Vargas salcedo no sólo son sus cuadros sino también una alusión que hace al respecto el profesor Muñoz Pal al terminar la lección inaugural de la nueva Cátedra de Anatomía, en 1922:

"y por último, que Vargas haga Anatomía, con su vena de artista, acostumbrado desde niño a manejar el lápiz y el pincel, como lo atestiguan tantas láminas de nuestra colección, hechas por él, es justo y no sorprende a nadie."

Estas obras, así como otras, se dibujarían como copias de grabados presentes en los libros Atlas of Human Anatomy and Surgery (1831-1854) J.M. Bourgery. Testut Latarjet y otros. Algunas serían de propia autoría. Hoy son monumento nacional (Cárdenas et al., 2017) (Fig. 4). Láminas como éstas se conservan aún en dependencias de anatomía de la Universidad de Concepción así como en la Universidad Católica en Chile Vistas por el autor, también se encuentran en dependencias de anatomia en Universidades extranjeras como Lisboa, Paris y museos como Neubourg, en Normandía. En la U. de Chile, la última lámina esta datada en el año 1956.

Rotafolio o papelógrafo: No hay registro sobre los inicios de esta modalidad de mostrar imágenes en clases en Chile, pero parece anteceder al uso de la electricidad, la que por análisis de fotografías, se infiere que llega esta última a la Escuela de Medicina alrededor del año 1915.

Consistía en el uso de láminas que, dispuestas unas sobre otras se descubrían progresivamente, ya sea sacándola de su fijación o dandolas vuelta, de ahí su nombre, en el que la primera lámina constituía el inicio de la presentación. Así, se disponía de muchas imágenes almacenadas en un espacio reducido, a diferencia de la exposición de las láminas anatómicas. La desventaja, el tamaño de la concurrencia no podía ser muy grande en virtud del tamaño de las imágenes manipulables por el operador, por lo que parece que se usaba más bien en entregar contenidos teóricos para grupos de trabajo en sala pequeños más que para ser utilizado en el aula principal.

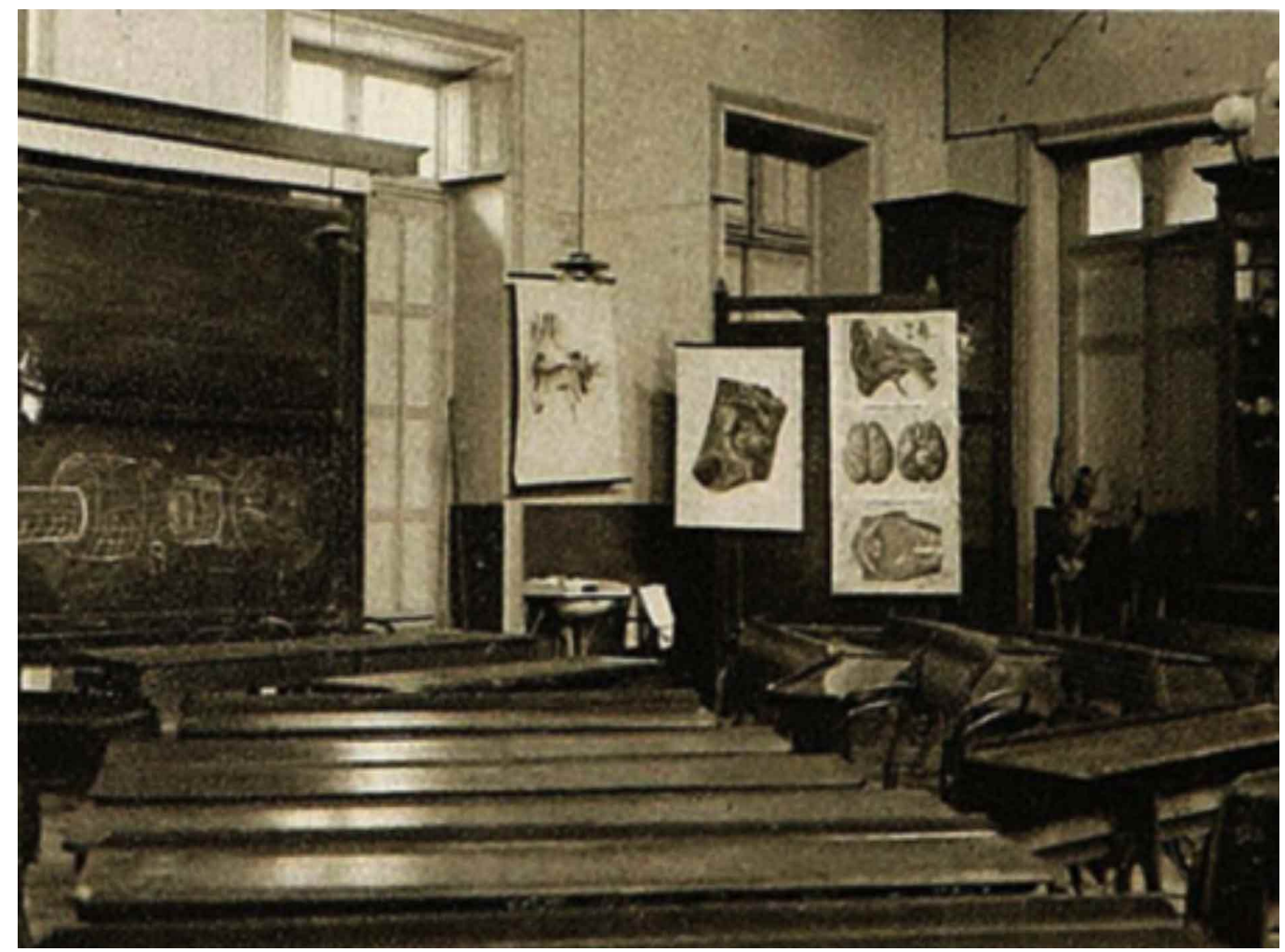

Fig. 4. Sala de clases de anatomía Universidad de Chile. Se aprecia una pizarra y la exposición de láminas anatómicas. La de la izquierda corresponde a una lámina de oido realizado por el entonces alumno Vargas Salcedo 10 años antes de la captura de esta imagen. Revista Sucesos, 2 de Diciembre 1905, Sección: Nuestros Establecimientos, en la Escuela de Medicina, pág. 588 . 


\section{B) Medios visuales secundarios}

Son medios en los cuales es imprescindible el uso de electricidad con el fin de lograr la proyección de imágenes previamente realizadas para ser proyectados sobre una superficie vertical y así lograr verla directamente o bien ampliarla a distancia, visualizando la imagen original con mejor calidad, a veces para un mayor $\mathrm{n}^{\mathrm{o}}$ de individuos.

Placas radiológicas: Si bien es cierto Wilhelm Conrad Röntgen había descubierto los rayos X ya a fines del siglo XIX,y que prontamente esta nueva tecnología sería aplicada a la práctica médica del estudio de imágenes, su aplicación en la enseñanza anatómica se retrasa algunos años.

Por ello, recién cuando en 1929 Muñoz Pal abandona transitoriamente la enseñanza por regresar a Europa, le sucede el Dr. Armando Alonso quién 2 años antes había viajado a Estados Unidos a las Universidades de Cornell, Columbia y Philadelphia para conocer la enseñanza de la anatomía y los sistemas de conservación cadavérica. Aprovecha la irrupción de exámenes radiológicos en la clínica primero como suele ocurrir con los exámenes, para aplicar el uso de las radiografías en la docencia anatómica en forma muy tímida inicialmente en los pasos prácticos alrededor de la década de los años 30 (Laval).

Posteriormente se dispondrían de negatoscopios, uno para cada pabellón y una base de placas obtenidas de distintos hospitales y servicios. Dispuestos al final de las demostraciones anatómicas prácticas con cadáveres, complementaba a éstas acercándola a la aplicación clínica de la anatomía.

Epidiascopio o proyector opaco: Desarrollado en los primeros años del siglo XX, este sistema consistía en la iluminación de un objeto opaco por una fuerte fuente de luz, para luego con espejos, proyectarla sobre un telón o pared, luego de regular la imagen con un lente de enfoque. Debía consumir mucha energía y a menudo dañaba la fuente de la imagen. Imágenes de hojas de libros de autores como Testut, Rouvière, Latarjet se proyectaban en esos años, así como fotografías o documentos (Barros \& Bravo, 2017; de Roo, 2017).

Retroproyectoras: En los años 1930, la pizarra y la tiza empiezan a reemplazarse progresivamente por retroproyectoras en la realización de las clases teóricas. Este aparato consistía en una caja con una fuente de luz que se proyectaba a una transparencia o lámina de acetato que se ponía sobre él a un lente que la proyectaba. Generaba mucho calor por lo que las fuentes se deterioraban frecuentemente y su ampolleta no duraba más de 100 h. Servía para proyectar dibujos, esquemas y textos transcritos.
Proyector de Diapositivas: Alrededor de los años 50 se desarrolla un sistema de proyección de placas transparentes de no más de 2 por $3 \mathrm{~cm}$ encuadradas en un marco de cartón plástico que se colocaban en un proyector que generaba una fuente de luz y calor, y que se montaban manualmente luego en un carro lineal o bien circular (carrusel) para su proyección. No era infrecuente que la placa se dañara al estar mucho tiempo expuesta. Las diapositivas se guardaban en unas páginas de plástico perforadas, que disponían de una especie de bolsillos o estuches transparentes, que se almacenaban en archivadores habitualmente por temas o bien por el origen de sus láminas según el libro utilizado. Se usaron desde la década de los 50 hasta alrededor de la década de los 90 y se dejaron de fabricar en el año 2004.

\section{C) Medios audiovisuales}

Son medios en los cuales, sumado a lo anteriormente descrito para los medios visuales secundarios, es posible agregar sonido a la presentación.

Diapocassete ó Diapófono: Fue necesario el desarrollo de medios que pudiesen grabar la voz humana para poder desarrollar esta metodología. Por ello, sólo después de la década de los 70 en que se fabrican las cintas magnéticas, inicialmente para poder grabar la voz, es que se puede implementar este novedoso sistema. Consistía en coordinar la voz grabada previamente de un narrador que relataba un guión previo, con el uso de imágenes de un rotafolio o bien un proyector de diapositivas, agregando música inclusive a las presentaciones. Se guardaba dicha información en una "cajita" o casette que permitía grabar audio por ambos lados. Posteriormente aparecerían las cintas magnéticas, lo que permite mejorar aún más la calidad del sonido (Daniel et al., 1999).

Videos: Al final de los años 80 y producto de una mejora en la grabación de sonidos e imagen en estas cintas, así como la disminución del ruido ambiental, se desarrollan sistemas de casette para video, en dos modalidades de formato Beta y VHS, consolidándose este último. Permite así el grabar imágenes de disecciones y demostraciones para trabajos prácticos demostrativos para los alumnos, pudiéndose almacenar gran cantidad de información en espacios relativamente reducidos.

Imagenología Digital: El uso de placas radiológicas en las actividades prácticas permaneció inalterable casi por 80 años. En el año 2008 y debido a la evidencia de problemas graves de archivo y pérdida del material, el suscrito aplica la metodología usada en la clínica sustituyendo el sistema de placas por imágenes digitales en pantallas usando una base de datos del Hospital Clínico de la Universidad de Chile. 
Se enriquecen así las imágenes radiológicas con tomografías y resonancias además de poder incorporar videos, pudiendo ordenar de mejor manera el material, visualizado éste ahora en monitores digitales que permiten agrandar, modificar y exponer de mejor manera dichas imágenes (Valenzuela, 2008), constituyendo el futuro de la imagenología que hoy se muestra en mesas digitales interactivas.

\section{D) Medios asociados a tecnologías de la información y} comunicación

Uso de medios utilizados más recientemente y que permite el procesamiento, modificación y visualización de imágenes para su difusión.

Proyección de imágenes digitales por computador o Data Show: Surge en el año de 1990, y viene a reemplazar definitivamente a las tradicionales diapositivas por su versatilidad en poder crear y modificar rápidamente las imágenes sin necesidad de utilizar otro medio físico, a la vez que permite almacenar mayor información siendo de fácil transporte, pudiendo agregar además videos, esquemas y poderse conectarse directamente a la internet. Utiliza un dispositivo que se conecta directamente con una computadora y que proyecta un haz de luz propio. Si bien es cierto se han agregado nuevos softwares y dispositivos de proyección led, su base de proyección y principios se mantienen. es cierto constituyen medios de apoyo para la docencia anatómica, no son utilizados en clases sino que son ideados para el reforzamiento o estudio posterior, claro ejemplo son atlas, programas multimediales y softwares demostrativos con variantes locales (Inzunza \& Bravo, 1999; Guiraldes et al., 2001). Actualmente existen además múltiples experiencias realizadas con imágenes 3D y hologramas para ser utilizados en docencia, como una herramienta más de apoyo al uso del cadáver en la docencia de la anatomía (Pujol, 2016).

\section{DISCUSIÓN}

La evolución de estos medios de enseñanza es permanente, desde el uso de elementos simples como el lápiz y la tiza, en su momento escasos e imprescindibles, hasta los últimos elementos computacionales. Se explica en parte al descubrimiento y llegada de la electricidad a la que se agregan los avances tecnológicos y el desarrollo de nuevos elementos ópticos de amplificación. Otra parte se explica también por el mayor número de alumnos en las aulas requiriendo por ello disponer de medios audiovisuales que permitiesen disponer de imágenes a distancia de buena calidad para una audiencia masiva. Unos aparecen, otros dejan de

Programas computacionales en línea o WEB: Si bien

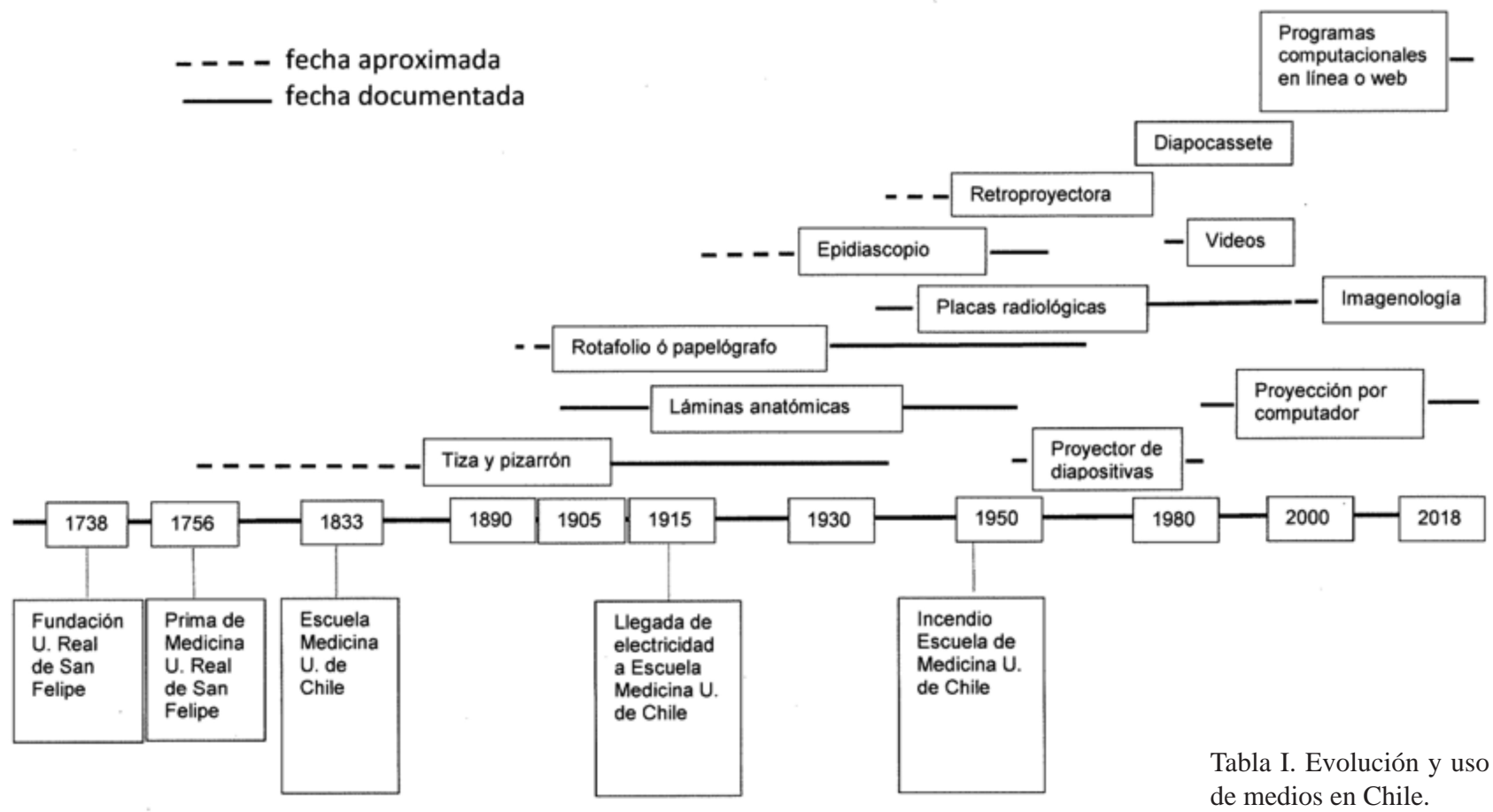


ejecutarse, siendo variable su permanencia en el tiempo (Tabla I). Lo que parece común sin embargo, es que esta evolución ha ocurrido en un orden similar en distintas partes del orbe, con algunas diferencias locales en cuanto a tiempo y oportundad.

Su uso se encuentra plenamente justificado en la docencia desde sus inicios pasando por la construcción de objetos de aprendizaje (Bucarey \& Alvarez, 2006) y desarrollo de programas multimediales foráneos y locales generados hasta la actualidad, lo cual cobra mayor importancia en momentos en que se enseña la anatomía de imágenes sin poder aún estandarizar su enseñanza de buena manera (Grignon et al., 2016).

CÁRDENAS, V. J. L. Teaching of anatomy. Use of media in the classroom. Int. J. Morphol., 37(3):1123-1129, 2019.

SUMMARY: There is little information about the use of media in the teaching of modern anatomy in its early years. This is perhaps explained because academics and students were more concerned with the content than with the media used for morphological teaching, obviously. Its use however is very important, because it modifies the way of teaching and building even the enclosures where teaching is taught, those that go from being places with a lot of natural light, to being rather dark closed enclosures and endowed with equipment with devices projectors of light at present. The present work therefore, intends to remind the new generations of methods used in the past, the beginning of the audiovisual techniques in the decade of the 30 s and the recent use of ICTs and show its development along with the technological changes in the anatomical teaching to this day, through general knowledge, evidence and graphic documents.

KEY WORDS: Teaching anatomy; History anatomy; Audio visual media.

\section{REFERENCIAS BIBLIOGRÁFICAS}

Adame Tomás, A. Medios audiovisuales en el aula. Rev. Digit. Innov. Exp. Educ., (19), 2009. Disponible en: http://online.aliat.edu.mx/Desarrollo/ Maestria/TecEducV2/Sesion5/txt/ANTONIO_ADAME_TOMAS01.pdf

Barros, P. \& Bravo, A. Proyectores. En: ¿Cómo funciona?. Sitio Web, 2017. Disponible en: http://web.archive.org/web/20070819032220/ www.librosmaravillosos.com/comofunciona/comofunciona34.html

Bucarey, S. \& Alvarez, L. Methodology to construct learning object for teaching human anatomy in integrated courses. Int. J. Morphol., 24(3):357-62, 2006

Cárdenas, V. J. L. History of anatomy in Chile. The beginnings. Int. J. Morphol., 35(3):958-69, 2017.

Cárdenas, V. J. L.; Dinator, E. M. \& Madariaga, L. J. Description of the anatomical plates of the Universidad de Chile, a national monument. Int. J. Morphol., 35(2):711-8, 2017.

Daniel, E. D.; Mee, C. D. \& Clark, M. H. Magnetic Recording. The First 100 Years. New York, IEEE Press, 1999. de Roo, H. R. A. Episcopes and Epidiascopes. Part 1. En: de Roo, H. R. A. de Luikerwaal. Sitio Web. Huizen, de Luikerwaal, 2017. Disponible en: https://www.luikerwaal.com/newframe_uk.htm?/epidia_uk.htm

Grignon, B.; Oldrini, G. \& Walter, F. Teaching medical anatomy: what is the role of imaging today? Surg. Radiol. Anat., 38(2):253-60, 2016.

Guiraldes, H.; Oddó, H.; Mena, B.; Velasco, N. \& Paulos, J. Teaching human anatomy: experience and challenge in a medical school. Rev. Chil. Anat., 19(2):205-12, 2001

Guzmán Cortés, L. Mis recuerdos de Estudiante. Santiago de Chile, Centro de Investigaciones de Historia de la Medicina de la Universidad de Chile, 1964.

Inzunza, O. \& Bravo, H. Impact of two software of human anatomy in the performance of the students practical knowledge. Rev. Chil. Anat., 17(2):205-9, 1999.

Laval, M. E. Evolución de la enseñanza de la anatomía en Chile. An. Chil. Hist. Med., 6(2):7-75, 1964.

Medina, J. T. La Medicina y los Médicos en la Real Universidad de San Felipe. Santiago de Chile, Litogr. Universo, 1928.

Pujol, S.; Baldwin, M.; Nassiri, J.; Kikinis, R. \& Shaffer, K. Using 3D modeling techniques to enhance teaching of difficult anatomical concepts. Acad. Radiol., 23(4):507-16, 2016.

Semir, M. Apuntes para la Historia de la Enseñanza en Chile. Santiago de Chile, Anales de la Universidad de Chile, 1860. pp.746-7.

Valenzuela, C. Formando a los Médicos del 2015. El Pulso, Revista de la Facultad de Medicina, Universidad de Chile, $N^{\circ} 51,27$ de mayo de 2008. Disponible en: http://elpulso.med.uchile.cl/20080527/noticia9.html

Dirección para correspondencia:

Julio Cardenas V.

Departamento de Anatomia y Medicina Legal

Facultad de Medicina

Universidad de Chile

Independencia 1027

Santiago

CHILE

Email: jcardena@med.uchile.cl

Recibido : 23-09-2018

Aceptado: 04-02-2019 